\title{
Altered gene expression correlates with DNA structure
}

\author{
Yoshinori Kohwi and Terumi Kohwi-Shigematsu \\ La Jolla Cancer Research Foundation, La Jolla, California 92037 USA
}

\begin{abstract}
We examined the participation of triplex DNA structure in gene regulation using a poly(dG)-poly(dC) sequence as a model. We show that a poly(dG)-poly(dC) sequence, which can adopt an intramolecular dG.dG.dC triplex under superhelical strain, strongly augments gene expression when placed $5^{\prime}$ to a promoter. The activity of this sequence exhibits a striking length dependency: dG tracts of 27-30 bp augment the expression of a reporter gene to a level comparable to that observed with the polyoma enhancer in mouse LTK $^{-}$cells, whereas tracts of 35 bp and longer have virtually no effect. A supercoiled plasmid containing a dG tract of $\mathbf{3 0}$ bp competes in vivo for a trans-acting factor as revealed by reduction in the reporter gene transcription driven by the (dG) $)_{29}$ /promoter of the test plasmid, while dGs of $35 \mathrm{bp}$ and longer in the competition plasmid failed to compete. In purified supercoiled plasmid DNA at a superhelical density of -0.05 , dG tracts of $32 \mathrm{bp}$ and longer form a triplex, whereas those of $\mathbf{3 0} \mathrm{bp}$ and shorter remain double-stranded under a PBS solution. These results suggest that a localized superhelical strain can exist, at least transiently, in mouse $\mathrm{LTK}^{-}$cells, and before being relaxed by topoisomerases this rapidly induces dG tracts of $35 \mathrm{bp}$ and longer to adopt a triplex preventing the factor from binding. Thus, these data suggest that a poly(dG)-poly(dC) sequence can function as a negative regulator by adopting an intramolecular triple helix structure in vivo.
\end{abstract}

[Key Words: Transcriptional regulation; negative supercoiling; poly $(\mathrm{dG})$-poly $(\mathrm{dC})$ sequence; $\mathrm{dG} . \mathrm{dG} . \mathrm{dC}$ triple helix; transcription factor]

Received August 6, 1991; revised version accepted October 1, 1991.

It has been assumed that transcriptional regulation is governed by proteins that interact with DNA through recognition of specific base sequences. Is DNA always a passive participant in its own utilization by providing sequences to be recognized by proteins? Because DNA is a flexible molecule and can form various structures other than the Watson-Crick B-form structure (non-B form DNA structure), DNA could utilize this potential to participate actively in biological reactions involving DNA. When introduced in the proper context, an anomalous structure, such as curved DNA, affects gene expression in Escherichia coli (Bracco et al. 1989).

Sequences residing in regulatory regions of genes are often found to be preferential targets, either in purified supercoiled plasmid DNA or chromosomal DNA in cells, for reaction with chemical probes and endonucleases such as $\mathrm{Sl}$, which preferentially attack singlestranded DNA (Larsen and Weintraub 1982; KohwiShigematsu et al. 1983; Bode et al. 1986; Kohwi-Shigematsu and Nelson 1988). The hyper-reactivity of these DNA regions to these probes suggests the formation of non-B form DNA structures in cells. Although the various types of sequences confer the non-B form DNA structure under superhelical strain, many of the S1-sensitive or chemical probe-reactive sequences have been identified as homopurine-homopyrimidine sequences.
For example, these homopurine-homopyrimidine sequences have been mapped in the regulatory regions of Drosophila heat shock genes (Mace et al. 1983; Siegfried et al. 1986), human c-myc gene (Boles and Hogan 1987), adenovirus major later promoter (Goding and Russell 1983), human $\epsilon$-globin gene (Allan et al. 1983), and chicken $\beta$-globin gene (Larsen and Weintraub 1982; Kohwi-Shigematsu et al. 1983; Nickol and Felsenfeld 1983; Kohwi 1989). These homopurine-homopyrimidine tracts are often found to bind sequence-specific factors, for example, a GA repeat element upstream of the Drosophila heat shock gene (Gilmour et al. 1989) and another type of a homopurine-homopyrimidine tract upstream of the human c-myc gene (Davis et al. 1989). Also, an erythrocyte-specific factor, BGPl, which binds to a poly $(\mathrm{dG})_{16}$ tract in the $5^{\prime}$-flanking region of the chicken adult $\beta$-globin gene, has been reported (Lewis et al. 1988), the binding of which requires $(\mathrm{dG})_{7}$ as a minimum recognition length (Clark et al. 1990). These factors bind to the corresponding homopurine-homopyrimidine sequences in the linear DNA fragments where altered structures cannot be formed.

To test whether DNA that forms a non-B-form DNA structure under superhelical strain plays a role in gene regulation by changing its structure, we chose the poly $(\mathrm{dG})-$ poly $(\mathrm{dC})$ sequence as a model. At a physiolog- 
ical $\mathrm{pH}$ and in the presence of $\mathrm{Mg}^{2+}$, a poly $(\mathrm{dG})-$ poly $(\mathrm{dC})$ sequence in supercoiled DNA folds sharply into halves at the center, forming a poly (dG)-poly $(\mathrm{dG})-$ poly $(\mathrm{dC})$ triple helix (abbreviated as dG.dG.dC triplex), with both halves of the poly (dG) tract and the $3^{\prime}$ half of the poly $(\mathrm{dC})$ tract leaving the $5^{\prime}$ half of the poly $(\mathrm{dC})$ tract base unpaired (Kohwi and Kohwi-Shigematsu 1988; Kohwi 1989) (see Fig. 4, below). This structure, which is distinct from the similar structure, consists of a protonated poly(dC)-poly(dG)-poly(dC) triplex (abbreviated as $\mathrm{dC}^{+} . \mathrm{dG} . \mathrm{dC}$ triplex) and single-stranded $5^{\prime}$ half of the $\mathrm{dG}$ tract that is commonly known as H-DNA, which occurs only at acidic $\mathrm{pH}$ without $\mathrm{Mg}^{2+}$ (Lyamichev et al. 1987; Kohwi-Shigematsu and Kohwi 1988). Recently, we reported that under a given ionic condition and superhelicity, there is a critical length requirement of the $d G$ tract for stabilization of the intramolecular dG.dG.dC triplex formation (Kohwi-Shigematsu and Kohwi 1991). Therefore, if there is a biological activity associated with the dG tract in vivo, this activity may exhibit a striking length dependency if the triplex formation is allowed in cells. Because the triplex formation requires superhelical strain, the present experiment addresses whether there is unconstrained superhelicity at any given time in eukary. otic cells.

Here, we report three independent observations regarding dramatic length dependency for poly(dG)poly(dC) sequences: (1) effects on gene expression, (2) binding by a trans-acting factor in vivo, and $(3)$ in vitro dG.dG.dC triplex formation. The results of each of these experiments identified a critical, sharp transition point in the length of the dG tracts. Taken together, these observations suggest that there is a structural transition for the poly(dG)-poly(dC) sequences that occurs in vivo and is responsible for altered gene expression.

\section{Results}

\section{Length-dependent effects on gene expression}

To examine whether poly(dG)-poly $(\mathrm{dC})$ sequences have any biological activity on gene expression, various lengths of the $(\mathrm{dG})_{n}$ tracts were inserted 23 bp from the $5^{\prime}$ end of the herpes simplex virus thymidine kinase (TK) promoter. This promoter is a 236-bp PvuIl-HincII fragment containing all three elements of the TK promoter (McKnight 1982), in addition to its 5' cap site. This was cloned next to the bacterial chloroamphenicol acetyltransferase (CAT) gene as shown in Figure 1A. These plasmids were transfected into mouse $\mathrm{LTK}^{-}$cells. We found that poly $(\mathrm{dG})-$ poly $(\mathrm{dC})$ sequences located $259 \mathrm{bp}$ from the cap site augmented gene expression, and this enhancing activity depended critically on the length of the dG tracts.

The insertion of poly(dG)-poly(dC) sequences of 27 (data not shown), 29, and 30 bp produced a strong transcriptional augmenting activity on CAT expression comparable to the polyoma enhancer (Fig. 1B, lanes 5,6). Surprisingly, the activity dropped dramatically for the $\mathrm{dG}$ tract of $33 \mathrm{bp}$ (data not shown) and remained very low for increasing dG lengths of 35 and 44 bp (Fig. 1B, lanes 7,8). The maximum transcriptional augmenting activity was seen with dG tracts of 29 and $30 \mathrm{bp}$, but a significant level of activity was also seen with the dG tract of $21 \mathrm{bp}$ (Fig. 1B, lane 4). A dG length shorter than $16 \mathrm{bp}$ had virtually no effect (data not shown). The transcriptional augmenting activity of the dG tracts requires the TK promoter (Fig. 1B, lane 9) and is independent of the orientation of the dG tracts (Fig. 1B, lanes 6,15).

If a trans-acting factor binds to the dG tract, the effect of the length of the dG tract on the regulation of CAT expression could be due to an alteration of the stereo-

\section{A}

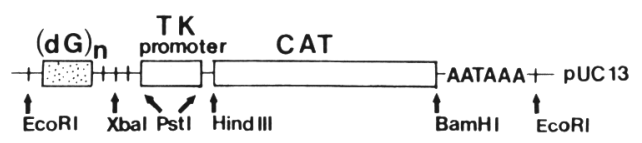

Figure 1. The effect of the $\mathrm{dG}$ tract on gene expression in vivo. $(A)$ The restriction map of the expression plasmid construct used in the experiment. The methods for constructing $\mathrm{dG}_{n}$ TKCAT, $\mathrm{dG}_{n}$ (-4 bp) TKCAT, and PyTKCAT are described in Materials and methods. $(B)$ Transfection of DNA into LTK ${ }^{-}$cells was performed with $2 \mu \mathrm{g}$ of pCAT (without TK promoter and $\left.\mathrm{dG}_{n}\right)$, pTKCAT, $(\mathrm{dG})_{n}$ TKCAT where $n=18,21,29,30,35$, and $44,(\mathrm{dG})_{29}$ CAT (promoter deleted), PyTKCAT, $\left(\mathrm{dG}_{29}(-4 \mathrm{bp})\right.$ TKCAT, $(\mathrm{dG})_{35}$ $(-4 \mathrm{bp})$ TKCAT, or $(\mathrm{dC})_{29}$ TKCAT (opposite orientation for the dG tract/ with $8 \mu \mathrm{g}$ of carrier pUCl8 vector plasmid as described in Materials and methods. Two days later, the CAT activities were measured. The fold induction for the CAT activity relative to that of PTKCAT is shown.

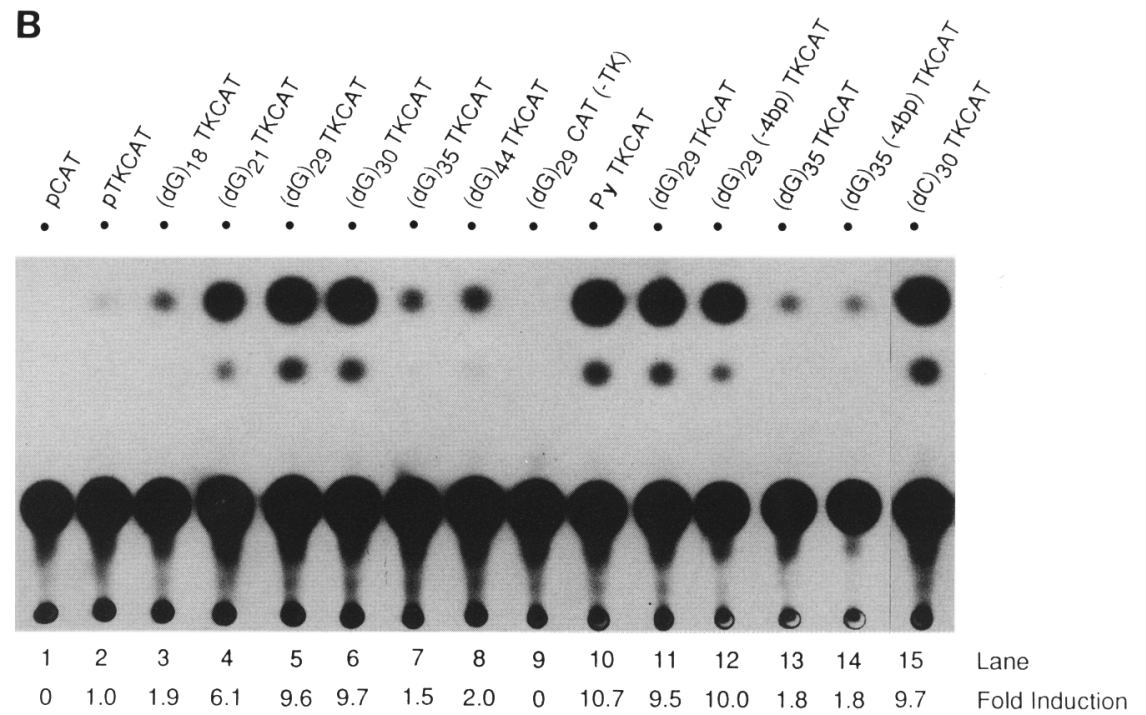


specific alignment between the factors binding to a specific position within a $\mathrm{dG}$ tract and the TK promoter. To examine this, we changed the original distance of $23 \mathrm{bp}$ between the dG tracts and the TK promoter by approximately one-half a helical turn by deleting $4 \mathrm{bp}$. This deletion had no effect on the strong transcriptional aug. menting activity of the 29-bp dG tract nor did it improve the very weak activity of the $35-\mathrm{bp} \mathrm{dG}$ tract (Fig $1 \mathrm{~B}$, lanes 11-14). Therefore, the transcriptional augmenting activity of dG tracts does not display the DNA turn dependence seen in the SV40 DNA early promoter (Takahashi et al. 1986). The length-dependent effect of poly(dG) tracts on gene expression cannot be explained by the deletion of the long dG tracts in $\mathrm{LTK}^{-}$cells. This was confirmed by sequence analysis on the plasmid DNAs that contain various lengths of dG tracts extracted from the LTK $^{-}$cells and amplified in bacteria. The maximal deletion frequency was $\sim 6 \%$ for the $44-\mathrm{bp} \mathrm{dG}$ tract and $<1 \%$ for the $35-$ bp dG tract (data not shown).

Enhancers are generally known to augment gene expression from distance in an orientation-independent manner (Schöler and Gruss 1984 and references therein). The effect by the dG tracts was abolished when a 600-bp sequence was inserted between the $\mathrm{dG}$ tracts and the TK promoter (data not shown). Thus, the dG tracts act as upstream activating elements rather than enhancers, even though the dG tracts can influence transcription in an orientation-independent manner as an enhancer.

\section{In vivo competition and gel mobility-shift assay}

We studied whether the strong transcriptional augmenting activity of poly(dG)-poly $(\mathrm{dC})$ sequences of certain lengths was the result of the binding of a trans-acting factor to the sequence. If there were such a trans-acting factor, it should be possible to titrate out the factor by adding excess amounts of a competitor plasmid that contains poly(dG)-poly(dC) sequences (Schöler and Gruss 1984). In parallel, we asked whether the structure of the target sequence influences binding by the factor. Our hypothesis is that a long, double-stranded dG tract may be preferred over a short tract for binding; however, when it exceeds a critical length where a triple helix structure is formed, the binding of the factor is inhibited. For the in vivo competition experiment, the transfection employing calcium phosphate was avoided because the intramolecular dG.dG.dC triplex formation is facilitated by divalent cations including $\mathrm{Ca}^{2+}($ Kohwi 1989). We employed a modified DEAE-Dextran transfection protocol as described in Materials and methods. To obtain the CAT activity of the uncompeted test plasmid to the level of at least $10 \%$ conversion of unacetylated chloramphenicol to the acetylated form, 1-2 $\mu \mathrm{g}$ of the test plasmid DNA should be used. Our modified DEAE-dextran transfection procedure gave the most reproducible results with a total of $10 \mu \mathrm{g}$ of DNA with pUC18 plasmid DNA as the carrier DNA. Under this condition, the level of CAT activity did not vary $>5 \%$ among different cell cultures transfected with a given DNA sample within the same experiment.
We cotransfected (dG) ${ }_{29}$ TKCAT plasmid (the test plasmid of $3.7 \mathrm{~kb}, 2 \mu \mathrm{g}$ ) and plasmid DNA containing only $(\mathrm{dG})_{n}$ where $n=13,18,21,29,30,35$, and $44 \mathrm{bp}$ (the competitor plasmids of $2.9 \mathrm{~kb}, 8 \mu \mathrm{g}$ ). As control competitor plasmids, we employed pUCl 8 vector plasmids alone (negative control) and pUC18, which contains only the TK promoter (positive control), because various protein factors have been reported to bind to this promoter region (for review, see Johnson and McKnight 1989). Data from a representative experiment employing 5-molar excess of competitor plasmid are shown in Figure 2A. The CAT activity of the test plasmid was not affected by cotransfecting with pUC18 plasmid (Fig. 2A, lane 1), whereas it was reproducibly reduced by $30 \pm 5 \%$ when cotransfected with the TK promoter-containing plasmid (Fig. 2A, lane 2). The CAT activity of the test plasmid was also reduced by $30 \pm 5 \%$ when cotransfected with the competitor plasmid containing dG tracts of 29 or 30 bp without the TK promoter (Fig. 2A, lanes 7,8 ). The percent inhibition of CAT activity again correlates with the length of the dG tract in the competitor plasmid: The percent inhibition increased with increasing length of $\mathrm{dG}$ tracts up to $30 \mathrm{bp}$, and it decreased dramatically beyond $35 \mathrm{bp}$ (Fig. 2A, lanes $4-10$ ). The plasmid containing both TK promoter and $(\mathrm{dG})_{29}$ competed more efficiently than the plasmid containing either sequence alone (Fig. 2A, lane 3). The PyTKCAT plasmid containing the polyoma enhancer (the PvuII-4 fragment) also competed to a moderate extent (Fig. 2A, lane 11). By increasing the ratio of competitor plasmid DNAs to the test plasmid, a maximum of $50-60 \%$ inhibition was seen with the plasmid containing $(\mathrm{dG})_{29-30}$ tracts. However, when higher ratios were used, the level of inhibition was subject to more variation among independent experiments. Nevertheless, it should be emphasized that all of our experiments showed efficient competition with dG tracts up to $30 \mathrm{bp}$ and abrupt loss of competing activity for the dG tracts of $35 \mathrm{bp}$ and longer. This transition point in length between 30 and 35 bp that distinguishes the competition activity is similar to that showing a dramatic difference in transcriptional enhancement. These results also support our hypothesis that a trans-acting factor that binds to the poly $(\mathrm{dG})-$ poly $(\mathrm{dC})$ tract exists in mouse $\mathrm{LTK}^{-}$cells and that the binding is affected by the DNA structure of the tract.

A gel mobility-shift assay with whole-cell extract (Eul et al. 1989) of mouse LTK $^{-}$cells also suggested that there is a factor that binds specifically to poly $(\mathrm{dG})-$ poly (dC) tracts (Fig. 2B). After mixing the whole-cell extract obtained from the mouse $\mathrm{L}$ cells and an end-labeled, linear DNA fragment containing a dG tract of $30 \mathrm{bp}$, we detected a band of slower migration. The intensity of this band decreased when the extract included either 10or 30-molar excess of unlabeled linear pUC18 containing $\mathrm{dG}$ tracts of 21,30, and $35 \mathrm{bp}$ (Fig 2B, lanes 4-9); however, addition of pUC18 alone (Fig. 2B, lanes 2,3) or the presence of the TK promoter (Fig. 2B, lanes 10,11) had no effect. When 30 -fold molar excess of competition plasmids with $\mathrm{dG}$ of 21,30 , or 35 bp was used, the band nearly vanished. Because we used linear rather than su- 
Figure 2. $(A)$ In vivo competition experiment. The percent inhibition of the CAT activity obtained as the result of the cotransfection is shown. A total of $10 \mu \mathrm{g}$ of DNA containing $2 \mu \mathrm{g}$ of the $(\mathrm{dG})_{29}$ TKCAT (test plasmid) and $8 \mu \mathrm{g}$ of competitor plasmids: (Lane 1) pUC18 plasmid, pUC13-containing; (lane 2) TK promoter (220-bp PvulI-HincII); (lane 3) (dG) ${ }_{29} \mathrm{TK}_{\text {; }}$ (lane 4) $(\mathrm{dG})_{13}$; (lane 5) $(\mathrm{dG})_{18}$; (lane 6) $(\mathrm{dG})_{21}$; (lane 7) $(\mathrm{dG})_{29}$; (lane 8$)(\mathrm{dG})_{30}$; (lane 9) $(\mathrm{dG})_{35} ;$ (lane 10) $(\mathrm{dG})_{44}$; (lane 11) the 191-bp PvuII-4 fragment (PyF101) of the polyoma enhancer was transfected with the procedure described in Materials and methods. The error bars indicate the level

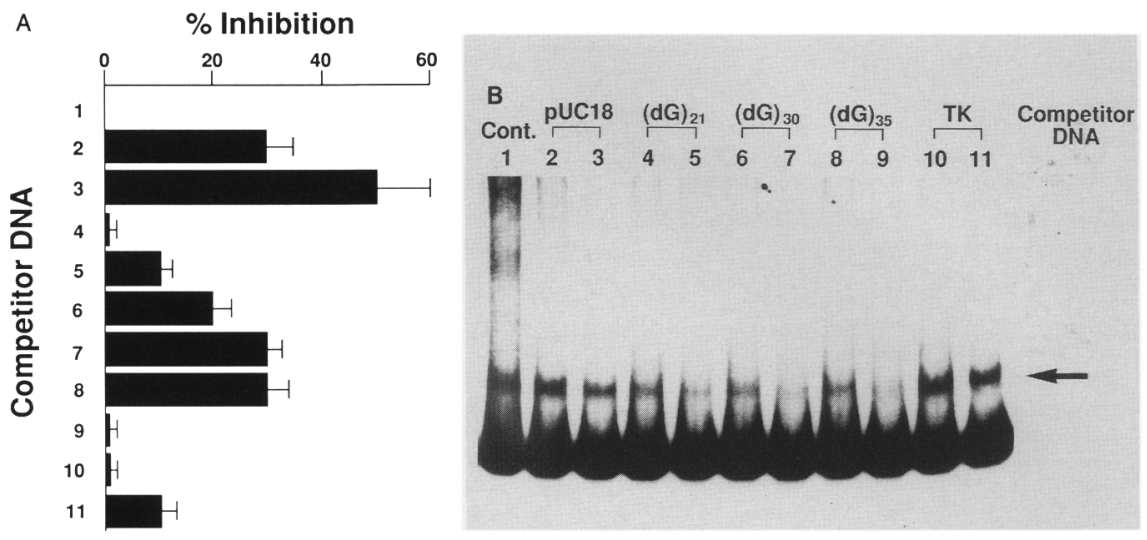
of fluctuation in the percent inhibition based on the CAT activity obtained for four different cell culture plates in two independent sets of experiments. The test gene competed with pUC18 (lane 1) was used as a standard and therefore has no error bar. This level of inhibition was highly reproducible among several independent experiments. $(B)$ The gel mobility-shift assay using poly(dG)-poly $(\mathrm{dC})$ sequence. The whole-cell extract was obtained from the mouse LTK $^{-}$cells. Radiolabeled HindIII-Bgll fragment, prepared from $0.1 \mu g$ of pCAT plasmid containing the $\mathrm{dG}_{30}$, was mixed in a total volume of $20 \mu$ l containing poly[d(I-C)] oligomer $(1 \mu \mathrm{g})$, mouse LTK ${ }^{-}$cell extracts $(5 \mu$ l containing 1-5 $\mu$ g protein), and HEPES buffer [final concentration: $10 \mathrm{~mm}$ HEPES (pH 7.9), $1 \mathrm{mM} \mathrm{DTT,} 50 \mathrm{~mm}$ KCl, 2.5 $\mathrm{mM} \mathrm{MgCl} 2,10 \%$ glycerol), with no competitor (lane 1); $1 \mu \mathrm{g}$ (lane 2) and $3 \mu \mathrm{g}$ (lane 3) of pUC18 plasmid DNA; $1 \mu \mathrm{g}$ (lane 4 ) and $3 \mu \mathrm{g}$ (lane 5) of pUC18 plasmid containing (dG) $21 ; 1 \mu \mathrm{g}$ (lane 6) and $3 \mu \mathrm{g}$ (lane 7) of (dG) $30 ; 1 \mu \mathrm{g}$ (lane 8) and $3 \mu \mathrm{g}$ (lane 9) of (dG) $35 ;$ or $1 \mu \mathrm{g}$ (lane 10 ) and $3 \mu \mathrm{g}$ (lane 11) of the TK promoter sequence. All competitor DNAs were digested with HindIII before use. After the mixtures were incubated at $30^{\circ} \mathrm{C}$ for $20 \mathrm{~min}$, DNA-protein complexes were separated on a $4 \%$ native polyacrylamide gel.

percoiled DNA, it is not surprising that no transition point in length that distinguishes the binding potential was observed in this experiment. Supercoiled DNA could not be used in this in vitro band-shift assay with whole-cell extract because of the topoisomerase activity. The enzyme activity is difficult to eliminate by a simple fractionation of the cell extract by chromatography. It apparently requires an extensive purification of the $\mathrm{dG}$ tract-binding protein before successfully removing the topoisomerase activity.

\section{Length requirement for dG.dG.dC triplex formation}

We have reported previously that either an intramolecular dG.dG.dC or $\mathrm{dC}^{+}$.dG.dC triplex formation depends on the length of poly(dG)-poly(dC) sequence (KohwiShigematsu and Kohwi 1991). The condition that we employed previously was $50 \mathrm{mM} \mathrm{Na}{ }^{+}$concentration at a bacterial superhelical density of -0.05 . To examine whether the length dependency that we observed for the effect of the sequence on gene expression and in vivo competition reflects the triplex formation beyond a certain length of the sequence, we performed the DNA structural analysis of various lengths of poly(dG)poly $(\mathrm{dC})$ sequences in PBS. Plasmid DNAs containing dG stretches of 21, 25, 27, 28,29,30,32, 35, and $44 \mathrm{bp}$ were constructed, and their triplex-forming potentials were examined under two slightly different ionic conditions: (1) $100 \%$ PBS [137 mM NaCl, $2.68 \mathrm{~mm} \mathrm{KCl}, 8 \mathrm{~mm}$ $\left.\mathrm{Na}_{2} \mathrm{HPO}_{4}, 1.47 \mathrm{mM} \mathrm{KH}_{2} \mathrm{PO}_{4}, \mathrm{pH} 7.4\right]$ with $2 \mathrm{mM} \mathrm{Mg}{ }^{2+}$; and (2) $80 \%$ of this solution (with $20 \% \mathrm{H}_{2} \mathrm{O}$ ). The structure was detected by reacting plasmid DNAs with chloroacetaldehyde (CAA), an unpaired DNA base-specific chemical probe, followed by the chemical cleavage method (Kohwi and Kohwi-Shigematsu 1988 and references therein). When a poly(dG)-poly(dC) tract forms a dG.dG.dC triplex, cytosines over the $5^{\prime}$ half of the $\mathrm{dC}$ tract that are not involved in the triplex formation are unpaired and are reactive with CAA. Thus, the dG.dG.dC triplex formation can be demonstrated by the cleavages of DNA at these cytosines, as shown by the appearance of new bands within sequencing ladders. Our results showed that in $100 \%$ PBS, a distinct transition point in lengths exists between 30 and 32 bp that separates double-stranded (up to $30 \mathrm{bp}$, Fig. 3B, lanes 1-6) versus triple helix structure $(32 \mathrm{bp}$ and longer; Fig. 3B, lanes 7-9) under the bacterial superhelical density of -0.05 . This result is well correlated with the lengthdependent CAT activity for dG tracts (Fig. 1B). In $80 \%$ PBS, a slightly lower ionic condition, the transition point in lengths occurred between 27 and 28 bp (Fig. 3A, lanes

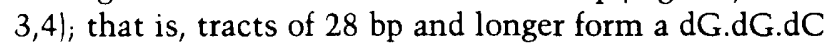
triplex, whereas those of $27 \mathrm{bp}$ and shorter form a double strand. We conclude that there is a sharp transition point in lengths of dG tracts between the triplex and B-form DNA structure under physiological ionic strength and at bacterial superhelical density. An increase of only two $\mathrm{dG}$ residues is sufficient to induce the triplex formation. The exact length at which the transition occurs is influenced by a slight difference in ionic strength.

\section{Discussion}

To examine the structure-function relationship of sequences that have the potential to adopt non-B-form DNA structures, we employed poly $(\mathrm{dG})-$ poly $(\mathrm{dC})$ sequences of various lengths as a model system. The formation of the intramolecular dG.dG.dC triplex is depen- 


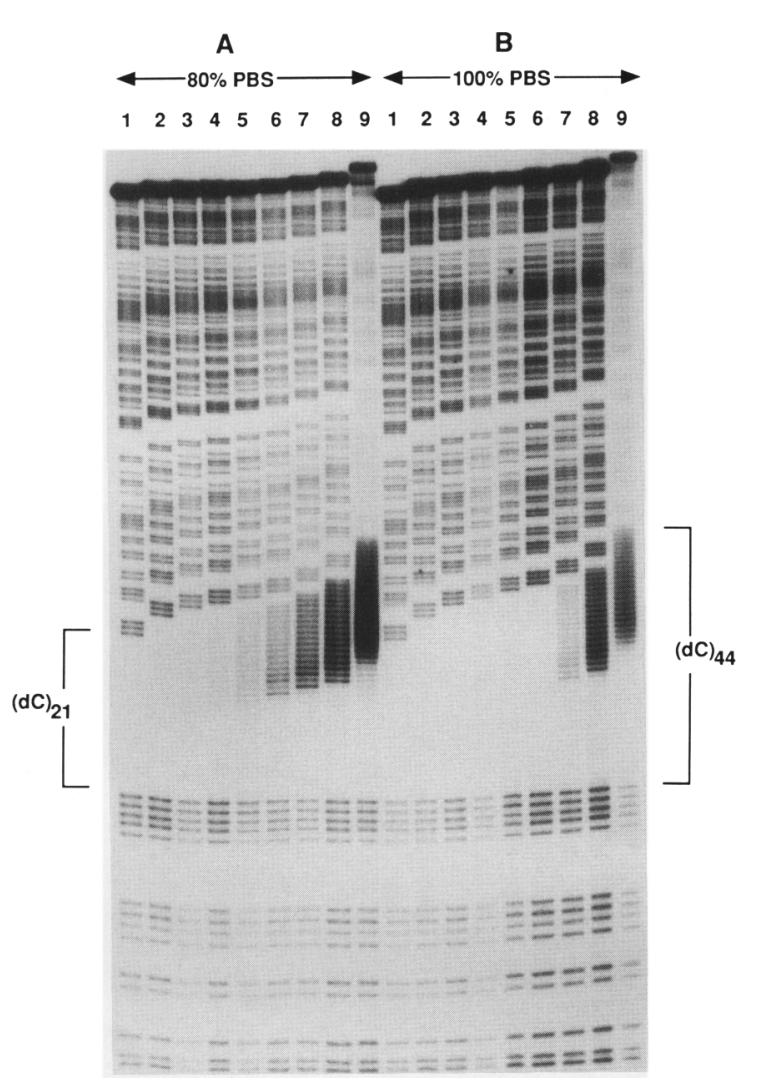

Figure 3. The length effect of the poly $(\mathrm{dG})-$ poly $(\mathrm{dC})$ sequence on the dG.dG.dC triplex formation. Supercoiled pCAT plasmid DNA harboring a poly $(\mathrm{dG})-$ poly $(\mathrm{dC})$ sequence of 21 bp (lane 1), 25 bp (lane 2), 27 bp (lane 3), 28 bp (lane 4), 29 bp (lane 5), 30 bp (lane 6), 32 bp (lane 7), 35 bp (lane 8), or 44 bp (lane 9) between the SmaI site and the SacI site was reacted with CAA in either $80 \%(A)$ or $100 \%(B)$ PBS with $2 \mathrm{mM} \mathrm{Mg}^{2+}$ ions. The HindIII$B g I I$ DNA fragment, end-labeled at the $3^{\prime}$ end of the HindIII site, containing the poly $(\mathrm{dG})$-poly $(\mathrm{dC})$ sequence was isolated from a native polyacrylamide gel and subjected to Maxam-Gilbert chemical sequencing reactions (Maxam and Gilbert 1977; Kohwi and Kohwi-Shigematsu 1988). The resulting DNA fragments were separated on an $8 \%$ urea-denaturing polyacrylamide gel. The regions for the $\mathrm{dC}$ tracts are indicated by a double-headed arrow.

dent on the sequence length and, as we show here, the sequences exert a length-dependent effect on gene expression.

Our results strongly suggest that non-B-form DNA structures may play an active role in gene expression. On the basis of our data, a possible mechanism by which this sequence may affect gene expression is shown in Figure 4. In this model, an intramolecular triplex formed by longer $\mathrm{dG}$ tracts in vivo prevents a trans-acting factor from binding and abolishing transcriptional enhancement. Altered gene expression could also be caused by the triplex formation disrupting local chromatin structure, for example, by changing nucleosome positioning.

There are sequence-specific factors reported that bind to homopurine-homopyrimidine sequences, including
$\mathrm{dG}$ tracts, located within regulatory regions of various genes (Lewis et al. 1988; Davis et al. 1989; Gilmour et al. 1989|. Under superhelical strain, these types of sequences form intramolecular triple helices (for review, see Wells et al. 1988) and other triplex-related DNA structures, including an intramolecular double triplex (Kohwi-Shigematsu and Kohwi 1991). Therefore, the results obtained with the model poly(dG)-poly(dC) sequence could be applied to further understand the role of homopurine-homopyrimidine sequences in gene regulation.

An intramolecular dG.dG.dC triplex can form only under superhelical stress; therefore, one must consider whether such supercoiling occurs in biological systems. In $E$. coli and yeast systems, it has been shown that active transcription of a gene induces local negative supercoiling $5^{\prime}$ and positive supercoiling $3^{\prime}$ of the gene (Liu and Wang 1987; Giaever and Wang 1988; Wu et al. 1988), as was shown in topoisomerase-defective mutant cells. In eukaryotes, the potential also exists to generate superhelical stress by the local removal of histone octamers. Recent in vitro experiments with the fibroin gene have shown that negative supercoiling plays an important role in eukaryotic transcription (Hirose and Suzuki 1988) and factor binding (Mizutani et al. 1991). Also, in vitro transcription of a topologically unconstrained template has been shown to transiently induce a B-Z transition in a region of alternating purines and pyrimidines as a result of transcription-induced negative supercoiling (Dröge and Nordheim 1991).

In our assay system we propose that sufficient local supercoiling is generated $5^{\prime}$ of the CAT gene to rapidly induce long $\mathrm{dG}$ tracts ( $33 \mathrm{bp}$ and longer) to fold into a triple helix before topoisomerases relax the DNA. The critical length of poly $(\mathrm{dG})$ tracts that separates the biological activity of this sequence may vary depending on the chemical and superhelical environments at specific sites in chromosomal DNA. Our results show that a slight difference in the ionic concentration leads to a reduction in the length of the poly $(\mathrm{dG})-$ poly $(\mathrm{dC})$ sequence that can adopt the intramolecular triplex by $4 \mathrm{bp}$. The superhelical environment at specific points upstream of an active gene may vary at different times during the transcription process. Therefore, it may be possible for relatively short tracts of homopurine-homopyridine sequences to fine-tune the level of transcription by making a rapid transition between $\mathrm{B}$ - and non-B-form DNA structures.

To prove that the dG.dG.dC triplex structure plays a role in gene regulation, it is important to detect the structure formation inside cells. Recently, by direct chemical probing, we demonstrated that this structure forms in E. coli cells transfected with the dG tract-containing plasmid DNAs in a dG-length and superhelicitydependent fashion (Y. Kohwi et al. 1991). Unfortunately, in situ probing of the DNA structure in mouse LTK $^{-}$ cells did not succeed due to the low amount of the transfected DNAs in these cells. The experiment was not successful even after attempting to amplify the signal for the DNA sequencing ladder by electroblotting the poly- 


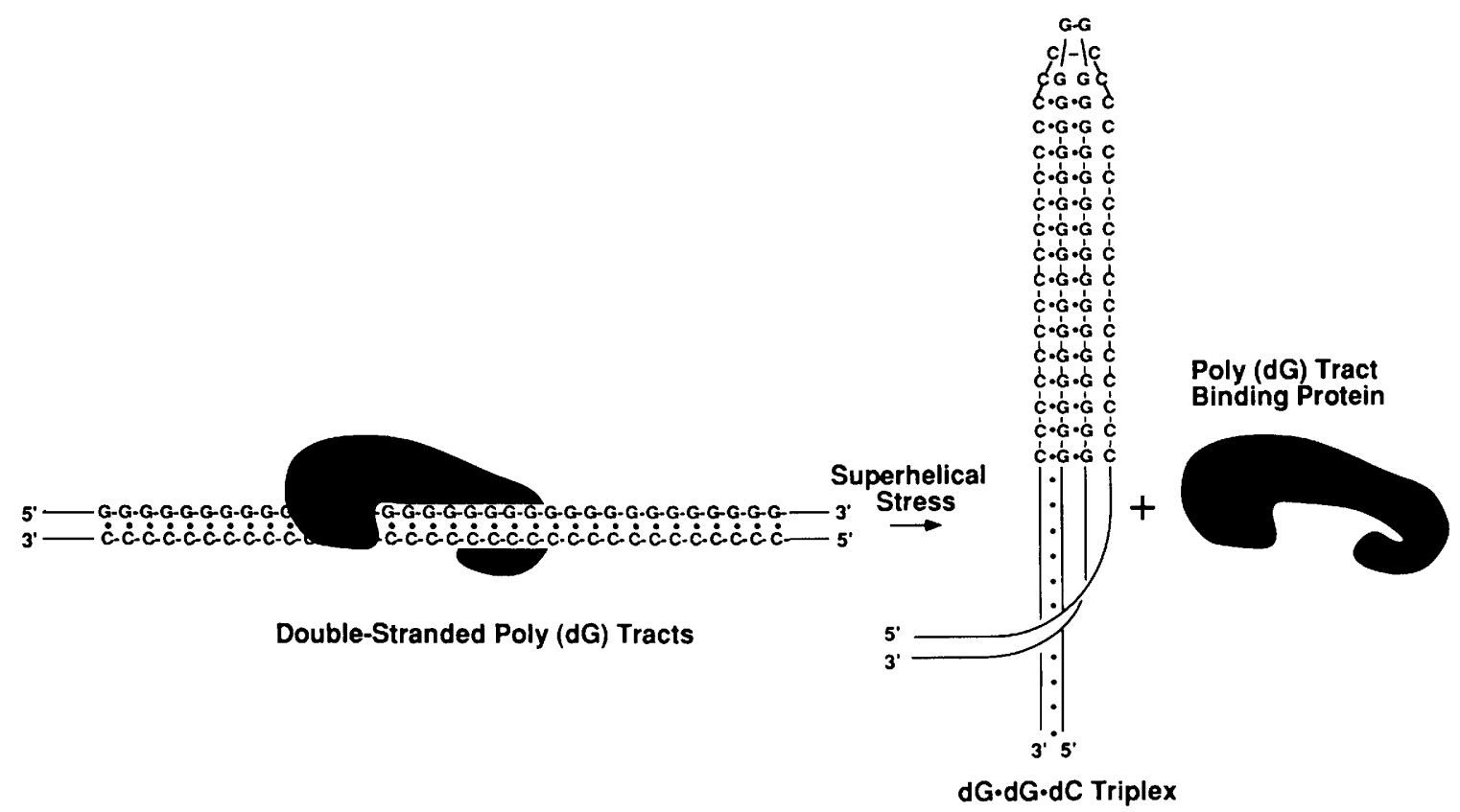

Figure 4. A model for negative regulation by poly $(\mathrm{dG})-$ poly $(\mathrm{dC})$ sequence. A model was postulated that the trans-acting factor $($ solid region) fails to bind to poly $(\mathrm{dG})$-poly(dC) sequence when the DNA folds into halves to form an intramolecular dG.dG.dC triplex. This model is consistent with the results that a 2- to 5 -bp difference in length of poly $(\mathrm{dG})-$ poly $(\mathrm{dC})$ sequence confers a dramatic variation in biological activities.

acrylamide gel onto a nylon membrane, followed by hybridization with RNA probes. Amplification of DNA with the primer-extension technique is unsuitable for our particular system, because polymerases terminate at the dG tracts (Baran et al. 1991). Therefore, we are currently studying the structure formation employing a plasmid DNA that can replicate to a high copy number in mouse $\mathrm{LTK}^{-}$cells.

On the basis of our results correlating the length dependency for the poly $(\mathrm{dG})$-poly $(\mathrm{dC})$ sequence activity in vivo and the dG.dG.dC formation in vitro, we speculate that non-B-form DNA-forming sequences in the regulatory regions participate actively in gene regulation, either positively or negatively, by making a structural transition in response to the local negative supercoiling.

\section{Materials and methods}

Chemicals

CAA was purchased from Fluka and doubly distilled (boiling point, $78-80^{\circ} \mathrm{C}$ ). The purified CAA was aliquoted in small fractions and stored at $-20^{\circ} \mathrm{C}$ until used. Hydrazine, formic acid, and piperidine were purchased from Sigma.

\section{Plasmid DNA}

The expression vector (pTKCAT) in pUC13 used in the transfection assay contains a 236-bp PvuII $\left(5^{\prime}\right.$ end $)$-HincII $\left(3^{\prime}\right.$ end $)$ fragment of the herpes simplex virus TK promoter placed in the PstI and HindIII sites in the polylinker region. One of the two PstI sites (the $3^{\prime}$ site) shown in Figure 1A is the internal site in the TK promoter located 22 bp upstream of the HinclI site. The pTKCAT contains the CAT gene and an AATAAA sequence for the polyadenylation signal (Linney and Donerly 1983). Varying lengths of poly(dG) tract were inserted into the SmaI-SacI sites in the expression vector by the G-C tailing method employing terminal transferase to generate $(\mathrm{dG})_{n}$ TKCAT; $n$ is the number of $\mathrm{dG}$ residues |for a detailed protocol, see Kohwi-Shigematsu and Kohwi 1991). The PyTKCAT construct contains a 191-bp PvulI-4 fragment (PyFl01) of the polyoma enhancer sequence placed $5^{\prime}$ of the TK promoter and the CAT gene (Linney and Donerly 1983). This PvuII-4 fragment has a tandem duplication of $54 \mathrm{bp}$ having a single-point mutation in each repeat (Fujimura et al. 1981). The $(\mathrm{dG})_{n}(-4$-bp $/$ TKCAT plasmid was constructed by deleting 4 bp between dG tracts and the TK promoter by first restricting the $(\mathrm{dG})_{n}$ TKCAT with $X b a I$ and HincII and then filling in the ends with Klenow large fragment and ligating.

\section{DNA transfection and the CAT assay}

A total of $10 \mu \mathrm{g}$ of DNA $8 \mu \mathrm{g}$ of pUCl8 vector and $2 \mu \mathrm{g}$ of test DNA (described in the legend to Fig. 1B)] was transfected as follows: The DNA was resuspended in $200 \mu$ l of buffer A [ $20 \mathrm{~mm}$ HEPES (pH 7.4-7.6) and $140 \mathrm{~mm} \mathrm{NaCl}$. This was mixed with $200 \mu \mathrm{l}$ of buffer A containing $20 \%$ dimethylsulfoxide (DMSO) (Sigma), $1 \mathrm{mg} / \mathrm{ml}$ of DEAE-dextran from Pharmacia (stock solution: $40 \%$ DMSO, $2 \mathrm{mg} / \mathrm{ml}$ of DEAE-dextran in buffer $\mathrm{A}$ |. Because there were no $\mathrm{Mg}^{2+}$ ions present in the solution, the plasmid DNAs had no dG.dG.dC triplex formed before they were introduced into the cells. The resulting DNA mixture was added to cells in a $10-\mathrm{cm}$ culture dish and incubated for $30 \mathrm{~min}$ at room temperature. The DNA mixture was aspirated and washed once with buffer $\mathrm{A}$ and replaced with complete media, and the dish was placed in a $\mathrm{CO}_{2}$ incubator with $5 \% \mathrm{CO}_{2}$. This 
is a simple, one-step transfection procedure that gives excellent reproducibility and transfection efficiency for mouse LTK cells. The high level of reproducibility was confirmed by cotransfecting with the human $\beta$-galactosidase gene driven by the human $\beta$-actin promoter and measuring the $\beta$-galactosidase activities of the cell extracts (Oshima et al. 1990). CAT assays were performed after 2 days, and the conversion was quantitated as described previously (Gorman et al. 1982).

\section{In vivo competition}

A total of $10 \mu \mathrm{g}$ of DNA containing $2 \mu \mathrm{g}$ of test plasmid $\left(\mathrm{pG}_{29}\right.$ TKCAT) and $8 \mu \mathrm{g}$ of competitor plasmids without the CAT gene [pUC1 8 plasmid, pUC13 containing the TK promoter, the TK promoter and $(\mathrm{dG})_{29},(\mathrm{dG})_{n}$, where $n=13,18,21,29,30,35$, and 44], and the 200-bp Pvull fragment of the polyoma enhancer were transfected at $1: 5$ molar ratio, as described in the legend to Fig. 2.

\section{Gel mobility-shift assay}

The gel mobility-shift assay with whole-cell extract of LTK cells was performed according to Eul et al. (1989). A radiolabeled DNA fragment containing the $\mathrm{dG}_{30}(0.1 \mu \mathrm{g})$ was mixed with poly[d(I-C)] oligomer $(1 \mu \mathrm{g})$, mouse $\mathrm{LTK}^{-}$cell extracts $(5 \mu)$ containing $1-5 \mu \mathrm{g}$ of protein), and HEPES buffer (final concentration, $10 \mathrm{~mm}$ HEPES (pH 7.9), $1 \mathrm{~mm}$ DTT, $50 \mathrm{~mm} \mathrm{KCl}, 2.5 \mathrm{~mm}$ $\mathrm{MgCl}_{2}, 10 \%$ glycerol], either with HindIII-digested competitor DNA containing various lengths of dG tracts or with no competitor in a total volume of $20 \mu \mathrm{l}$, as described in Figure 2B. The mixture was incubated at $30^{\circ} \mathrm{C}$ for $20 \mathrm{~min}$. The DNA-protein mixtures were then loaded onto a $4 \%$ native polyacrylamide gel and run at $4^{\circ} \mathrm{C}$. The gel was dried and exposed to an X-ray film.

\section{Mapping of CAA-modified sites}

CAA-modified sites were determined as described in Kohwi and Kohwi-Shigematsu (1988). Supercoiled plasmid DNA containing varying lengths of poly (dG) tracts was reacted with $2 \mu \mathrm{l}$ of CAA in $100-\mu$ l reaction volume of either $100 \%$ PBS or $80 \%$ PBS at $37^{\circ} \mathrm{C}$ for $\mathrm{l} \mathrm{hr}$. CAA-modified DNAs were made into $0.3 \mathrm{M}$ $\left[\mathrm{Na}^{+}\right]$and precipitated successively with 3 volumes of ethanol. Two micrograms of DNA was digested with HindIII, and the 3 end was labeled with Klenow large fragment of DNA polymerase I. The end-labeled DNA was cleaved further at a distal site with the second restriction enzyme, BgII. The DNA fragment containing the poly $(\mathrm{dG})$-poly $(\mathrm{dC})$ sequence was isolated from a native polyacrylamide gel, and the DNA was eluted from the gel in an elution buffer $\left[0.5 \mathrm{M}\left(\mathrm{NH}_{4}\right) \mathrm{OAc}, 1 \mathrm{~mm}\right.$ EDTA, $\left.0.1 \% \mathrm{SDS}\right]$ at $42^{\circ} \mathrm{C}$ overnight. The DNA isolated from a large segment of acrylamide gel was cleaned further by Geneclean II (B10-101) and was then subjected to hydrazine or formic acid reaction followed by piperidine reaction as described in Maxam and Gilbert (1977). The chemically cleaved DNA was heat denatured and loaded onto a $8 \%$ urea-denaturing polyacrylamide gel.

\section{Acknowledgments}

This work was supported by grants from the National Institutes of Health (ROI CA39681 to T.K.-S. and ROI CA51377 to Y.K.), by funds provided by the Cigarette and Tobacco Surtax Fund of the State of California through the Tobacco-Related Disease Research Program of the University of California (1KT98 to Y.K.l, and by an American Cancer Society Faculty Award to T.K.-S. We thank Drs. G. Felsenfeld, A. Travers, and H. Weintraub for valuable discussions. We thank Drs. R. Sinden, B.
Oshima, C. Hauser, and W. Reynolds for critically reading the manuscript and $C$. Baker for manuscript preparation. We are also indebted to $\mathrm{H}$. Tran for excellent technical assistance.

The publication costs of this article were defrayed in part by payment of page charges. This article must therefore be hereby marked "advertisement" in accordance with 18 USC section 1734 solely to indicate this fact.

\section{References}

Allan, M., W.G. Lanyon, and J. Paul. 1983. Multiple origins of transcription in the $4.5 \mathrm{~kb}$ upstream of the $\mathrm{e}$-globin gene. Cell 35: 187-197.

Baran, N., A. Lapidot, and H. Manor. 1991. Formation of DNA triplexes accounts for arrests of DNA synthesis at $\mathrm{d}(\mathrm{TC})_{\mathrm{n}}$ and $\mathrm{d}(\mathrm{GA})_{\mathrm{n}}$ tracts. Proc. Natl. Acad. Sci. $88: 507-511$.

Bode, J., H.-J. Pucher, and K. Maass. 1986. Chromatin structure and induction-dependent conformational changes of human interferon- $\beta$ genes in a mouse host cell. Eur. I. Biochem. 158: $393-401$.

Boles, T.C. and E. Hogan. 1987. DNA structure equilibria in the human c-myc gene. Biochemistry 26: 367-376.

Bracco, L., D. Kotlarz, A. Kolb, S. Diekmann, and H. Buc. 1989. Synthetic curved DNA sequences can act as transcriptional activators in Escherichia coli. EMBO I. 8: 4289-4296.

Clark, S.P., C.D. Lewis, and G. Felsenfeld. 1990. Properties of $\mathrm{BGPl}$, a poly(dG)-binding protein from chicken erythrocytes. Nucleic Acids Res. 18: 5119-5126.

Davis, T.L., B. Firulli, and A.J. Kinniburgh. 1989. Ribonucleoprotein and protein factors bind to an H-DNA-forming c-myc DNA element: Possible regulators of the c-myc gene. Proc. Natl. Acad. Sci. 86: 9682-9686.

Dröge, P. and A. Nordheim. 1991. Transcription-induced conformational change in a topologically closed DNA domain. Nucleic Acids Res. 19: 2941-2946.

Eul, J., M.E. Meyer, L. Tora, M.T. Bocquel, C. Quirin-Stricker, P. Chambon, and H. Gronemeyer. 1989. Expression of active hormone and DNA-binding domains of the chicken progesterone receptor in E. coli. EMBO J. 8: 83-90.

Fujimura, F.K., P.L. Deininger, T. Friedmann, and E. Linney. 1981. Mutation near the polyoma DNA replication origin permits productive infection of $\mathrm{F} 9$ embyonal carcinoma cells. Cells 23: 809-814.

Giaever, G.N. and J.C. Wang. 1988. Supercoiling of intracellular DNA can occur in eukaryotic cells. Cell 55: 849-856.

Gilmour, D.S., G.H. Thomas, and S.C.R. Elgin. 1989. Drosophila nuclear proteins bind to regions of alternating $C$ and $T$ residues in gene promoters. Science 245: 1487-1490.

Goding, C.R. and W.C. Russell. 1983. TI S1 sensitive sites in adenovirus DNA. Nucleic Acids Res. 11: 21-36.

Gorman, C.M., L.F. Moffat, and B.H. Howard. 1982. Recombinant genomes which express chloramphenicol acetyltransferase in mammalian cells. Mol. Cell. Biol. 2: 1044-1051.

Hirose, S. and Y. Suzuki. 1988. In vitro transcription of eukaryotic genes is affected differently by the degree of DNA supercoiling. Proc. Natl. Acad. Sci. 85: 718-722.

Johnson, P.F. and S.L. McKnight. 1989. Eukaryotic transcriptional regulatory proteins. Annu. Rev. Biochem. 58: 799839.

Kohwi, Y. 1989. Cationic metal-specific structures adopted by the poly(dG) region and the direct repeats in the chicken adult $\beta^{A}$ globin gene promoter. Nucleic Acids Res. 17: 44934502 .

Kohwi, Y. and T. Kohwi-Shigematsu. 1988. Magnesium iondependent triple-helix structure formed by homopurine-ho- 
mopyrimidine sequences in supercoiled plasmid DNA. Proc. Natl. Acad. Sci. 85: 3781-3785.

- 1991. Detection of triple-helix related structures adopted by poly $(\mathrm{dG})$-poly $(\mathrm{dC})$ sequences in supercoiled DNA. Nucleic Acids Res. 19: 4267-4271.

Kohwi-Shigematsu, T. and J. Nelson. 1988. The chemical carcinogen, chloroacetaldehyde, modifies a specific site within the regulatory sequence of human cytomegalovirus major immediate early gene in vivo. Mol. Carcinogenesis 1: 20-25.

Kohwi-Shigematsu, T., R. Gelinas, and H. Weintraub. 1983. Detection of an altered DNA conformation at specific sites in chromatin and supercoiled DNA. Proc. Natl. Acad. Sci. 80: $4389-4393$.

Kohwi, Y., S. Malkhosyan, and T. Kohwi-Shigematsu. 1992. Intramolecular dG.dG.dC triplex was detected in E. coli cells. I. Mol. Biol, (in press).

Larsen, A. and H. Weintraub. 1982. An altered DNA conformation detected by $\mathrm{S} 1$ nuclease occurs at specific regions in active chick globin chromatin. Cell 29: 609-622.

Lewis, C.D., S.P. Clark, G. Felsenfeld, and H. Gould. 1988. An erythrocyte-specific protein that binds to the poly(dG) region of the chicken $\beta$-globin promoter. Genes \& Dev. 2: 863-873.

Linney, E. and S. Donerly. 1983. DNA fragments from F9 PyEC mutants increase expression of heterologous genes in transfected F9 cells. Cell 35: 693-699.

Liu, L.F. and J.C. Wang. 1987. Supercoiling of the DNA template during transcription. Proc. Natl. Acad. Sci. 84: 7024-7027.

Lyamichev, V.I., S.M. Mirkin, and M.D. Frank-Kamenetiskii. 1987. Structure of $(\mathrm{dG})_{\mathrm{n}} \cdot(\mathrm{dC})_{\mathrm{n}}$ under superhelical stress and acid pH. I. Biomol. Struct. \& Dyn. 5: 275-282.

Mace, H.A.F., H.R.B. Pelham, and A.A. Travers. 1983. Association of an S1 nuclease-sensitive structure with short direct repeats 5' of Drosophila heat shock genes. Nature 304: 555557.

Maxam, A. M. and W. Gilbert. 1977. A new method for sequencing DNA. Sequencing end-labeled DNA with base-specific chemical cleavages. Proc. Natl. Acad. Sci. 74: 560-564.

McKnight, S.L. 1982. Functional relationships between transcriptional control signals of the thymidine kinase gene of herpes simplex virus. Cell 31: 355-365.

Mitzuani, M., T. Ohta, H. Watanabe, H. Handa, and S. Hirose. 1991. Negative supercoiling of DNA facilitates an interaction between transcription factor IID and the fibroin gene promoter. Proc. Natl. Acad. Sci. 88: 718-722.

Nickol, J.M. and G. Felsenfeld. 1983. DNA conformation at the $5^{\prime}$ end of the chicken adult $\beta$-globin gene. Cell 35: 467-477.

Oshima, R.G., L. Abrams, and D. Kulesh. 1990. Activation of an intron enhancer within the keratin 18 gene by expression of c-fos and c-jun in undifferentiated F9 embryonal carcinoma cells. Genes \& Dev. 4: 835-848.

Schöler, H.R. and P. Gruss. 1984. Specific interaction between enhancer-containing molecules and cellular components. Cell 36: 403-411.

Siegfried, E., G.H. Thomas, U.M. Bond, and S.C.R. Elgin. 1986. Characterization of a supercoil-dependent $S 1$ sensitive site 5 ' to the Drosophila melanogaster hsp 26 gene. Nucleic Acids Res. 14: 9424-9244.

Takahashi, K., M. Vigneron, H. Matthes, A. Wildeman, M. Zenke, and P. Chambon. 1986. Requirement of stereospecific alignments for initiation from the simian virus 40 early promoter. Nature 319: 121-126.

Wells, R.D., Collier, D.A., Hanvey, J.C., Shimizu, M., and Wohlrab, F. 1988. The chemistry and biology of unusual DNA structures adopted by oligopurine.oligopyrimidine sequences. FASEB I. 2: 2939-2949.

Wu, H.-Y., S. Shyy, J.C. Wang, and L.F. Liu. 1988. Transcription generates positively and negatively supercoiled domains in the template. Cell 53: 433-440. 


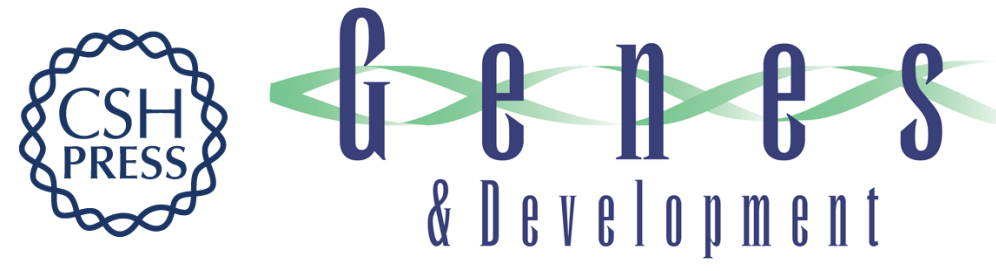

\section{Altered gene expression correlates with DNA structure.}

Y Kohwi and T Kohwi-Shigematsu

Genes Dev. 1991, 5:

Access the most recent version at doi:10.1101/gad.5.12b.2547

References This article cites 36 articles, 12 of which can be accessed free at: http://genesdev.cshlp.org/content/5/12b/2547.full.html\#ref-list-1

License

Email Alerting

Receive free email alerts when new articles cite this article - sign up in the box at the top Service right corner of the article or click here.

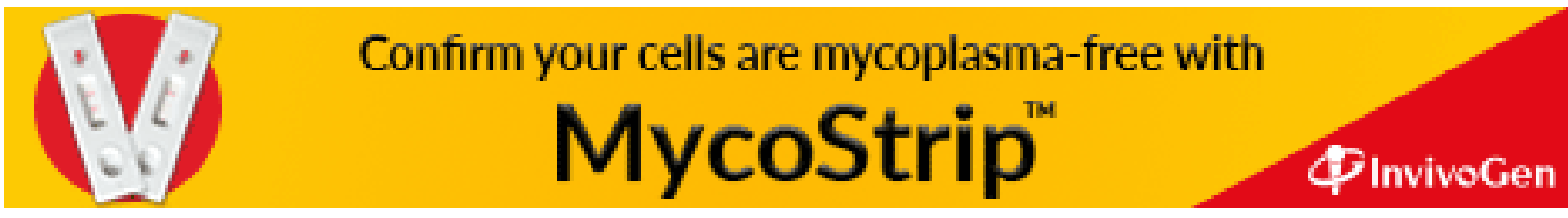

